\title{
From Wire to Seamless Flow-Formed Tube: Leveraging the Combination of Wire Arc Additive Manufacturing and Metal Forming
}

\author{
A. SHIRIZLY ${ }^{1}$ and O. DOLEV (i) ${ }^{1,2}$ \\ 1.-Faculty of Mechanical Engineering, Technion, 3200003 Haifa, Israel. 2.—e-mail: dolev.ohad@ \\ gmail.com
}

Flow forming is a metal-forming process for producing axisymmetric hollowed tubes starting from cylindrical workpieces. In cases where the preformed tube includes defects, impurities or inconsistencies, the final product may not withstand the required standard. In this work, the preformed tubes were produced by metal wires melted into the desired geometry using a gas-metal arc-welding robot. Two geometries were built to allow either forward or backward tube spinning of parts from ER-70S-6 and AWS ER316L welding wires. Following the building process, the parts were machined to fit a flowforming operation. The mechanical and metallurgical properties of the wires, preformed cylinders and final tubes were compared with conventionally manufactured material. Results indicate that the mechanical properties of the products of the proposed process were superior to those of conventional processing. Applying flow forming to wire-arc additive manufacturing yields a deeper understanding of the material qualities over a large building envelope and can be used as valid quality criteria for the additive manufacturing process qualification.

\section{INTRODUCTION}

Flow forming is a metal forming technology used to produce seamless thin-wall tubes. Flow-formed tubes can fulfill the requirements of high specific strength, tight tolerances and excellent surface finish. During the forming operation, high local deformation affects the material strain hardening and thus a low-strength starting material yields a high-strength finished product. ${ }^{1}$ Seamless flowforming tubes are applicable for the automobile, aviation and aerospace industires as lightweight pressure vessels.

Recently, Motgharea et al. ${ }^{2}$ reviewed the parameters of the flow forming process, and Marini et el. ${ }^{3}$ reviewed the methodologies of the process and possible influence of process parameters on the final product accuracy. Multiple parameters, such as a high level of plastic deformation along with geometrical sensitivity and process variables under dynamic conditions, influence the flow-forming operation; thus, it relies mainly on experience and practice. The forming operation includes a predetermined thickness reduction of the preform tube wall. ${ }^{4}$ Gur and Tirosh ${ }^{5}$ describe the flowforming process in the analytical model as a combination of rolling and extrusion. Although some researchers have developed finite element models to simulate the process based on experimental conditions ${ }^{6-8}$ and many more parameters, in practice, these models have not succeeded in replacing the operators' and engineers' experience as a practical guide.

In general, the common preformed tube for the flow-forming process is prepared by extrusion or forging processes followed by heat treatment and machining. ${ }^{9-11}$ The possibility of building a preform specimen using wire arc additive manufacturing (WAAM) was not investigated or introduced in this work. The idea of using a WAAM process was first introduced by Baker $^{12}$ in 1925 as a US patent: "Method of making decorative articles." Although most of the work was carried out manually, Baker predicted the advantages of his patented method and wrote: "I need not necessarily manipulate the electrode by hand. If the electrode is to be 
manipulated to form a number of articles having like contour, pantographic or other apparatus, such as is used by engravers, may be employed. This invention allows a wide latitude of design and manipulation." In fact, Baker had predicted the development of automation and robotics in this field.

In recent years, the development and use of the WAAM process has increased rapidly. In 2018, Derekar ${ }^{13}$ published a review of WAAM and focused on the advances in WAAM of aluminum from the design stage and the mechanical properties of the manufactured product. Frazier ${ }^{14}$ presented an additional review with emphasis on process and business considerations associated with WAAM performance in which he compared the powder bed, powder feed and wire feed technologies.

The process strategy and use of robotic systems to control the weld path influence the quality of the final product. ${ }^{15-19}$ Sames et al. ${ }^{20}$ have also investigated the metallurgy of metal additive manufacturing for several additive techniques and report on tensile test results as a function of the material, sample orientation and build technique. Xu et al. ${ }^{21}$ presented a microstructural evaluation of mechanical properties of materials produced by the WAAM process of maraging steel and mapped the mechanical and metallurgical properties as a function of the sample location and orientation.

Most of the published work deals with the mechanical and metallurgical aspects of the built parts and suggests a specific tool path generation method. In most cases, the built parts are heat treated and machined as a final product or tools such as forging dies ${ }^{22}$ or forming tools. ${ }^{23}$ The idea to apply an online cold-rolling process to the linear additive manufacturing of Ti-6Al-4V was presented by researchers at Cranfield University. ${ }^{24-26}$ The interpass cold rolling is presented as a mechanism to improve the microstructure and mechanical properties.

In this work, the built parts will be used as preformed parts to be flow formed into final seamless tubes. The mechanical and metallurgical aspect will be explored for the preform WAAM tube as well as for the final flow-formed tubes.

\section{EXPERIMENTAL}

The experimental part of this work includes the building of preforms for the flow-forming operation, metal-forming operations (forward and backward flow forming), and mechanical and metallurgical evaluation of the parts at various work stages of the process.

A schematic block diagram of the entire process is shown in Fig. 1, designed to demonstrate the manufacturing of parts using the WAAM process. The process consisted of a material source (i.e., welding wire), welding manipulator [welding robot or computer numerically controlled (CNC) welding

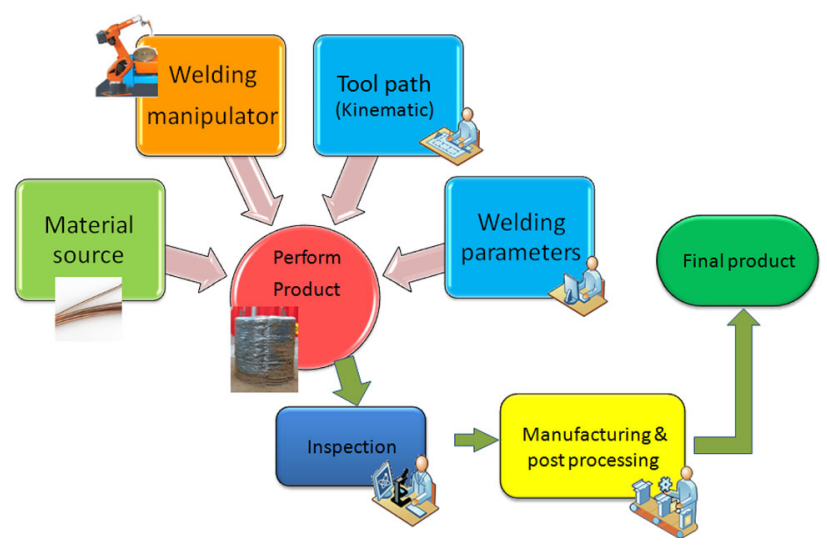

Fig. 1. Schematic representation of the wire arc additive manufacturing (WAAM) process.

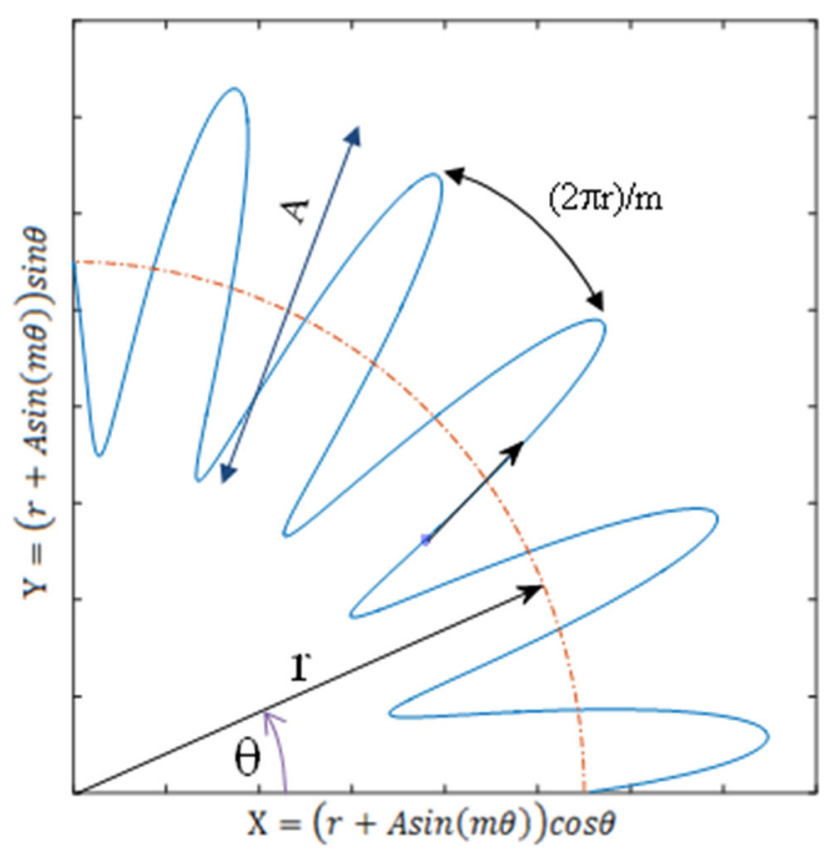

Fig. 2. Tool path for axisymmetric parts.

machine], tool path generator for the desired geometry and welding parameters (wire feed, required energy, welding speed, protecting gas). Only when the above combination of parameters works together can the required preform qualities can be accomplished. In most WAAM applications, the built parts are near-net shapes. A heat treatment and final machining are then applied to the final product. In the current study, the mechanical properties of the preforms were tested and the metal-forming operations applied.

\section{Tool Path}

Prior researchers have proposed different strategies for the use of the robotic system controlling the weld tool path according to their individual 


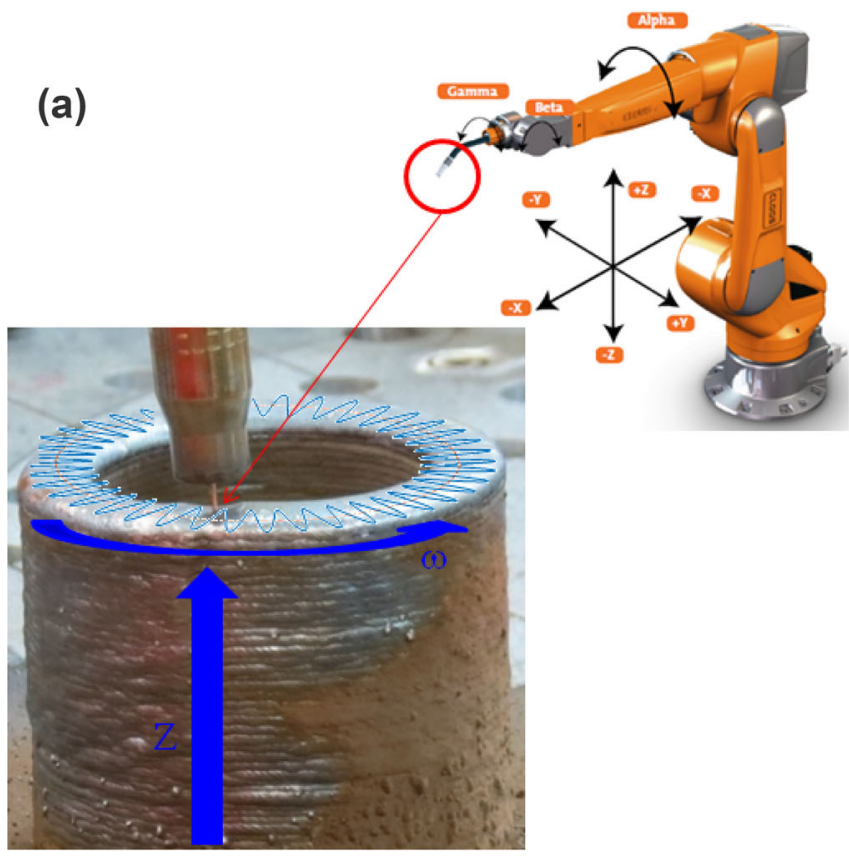

(b)

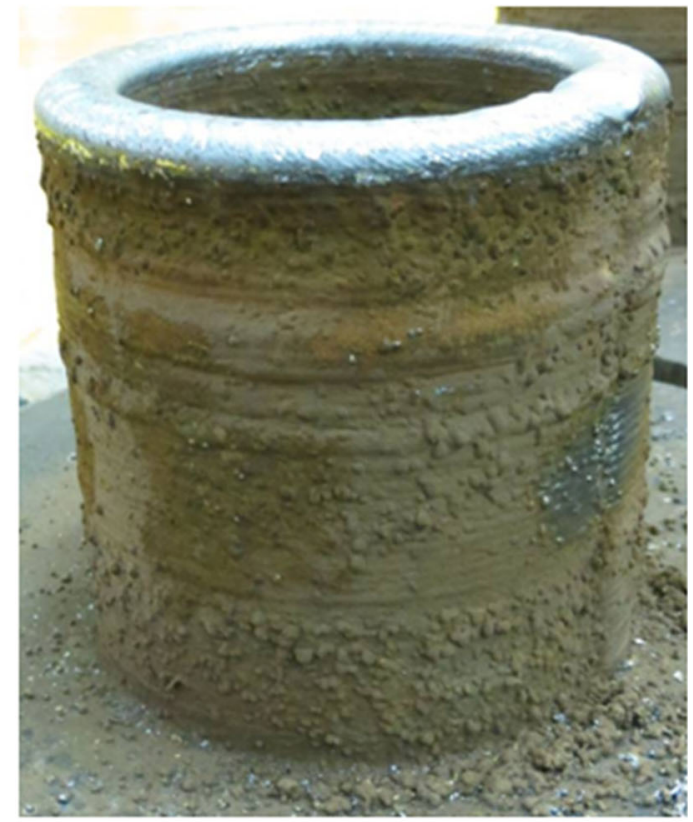

Cylindrical shape

(c)

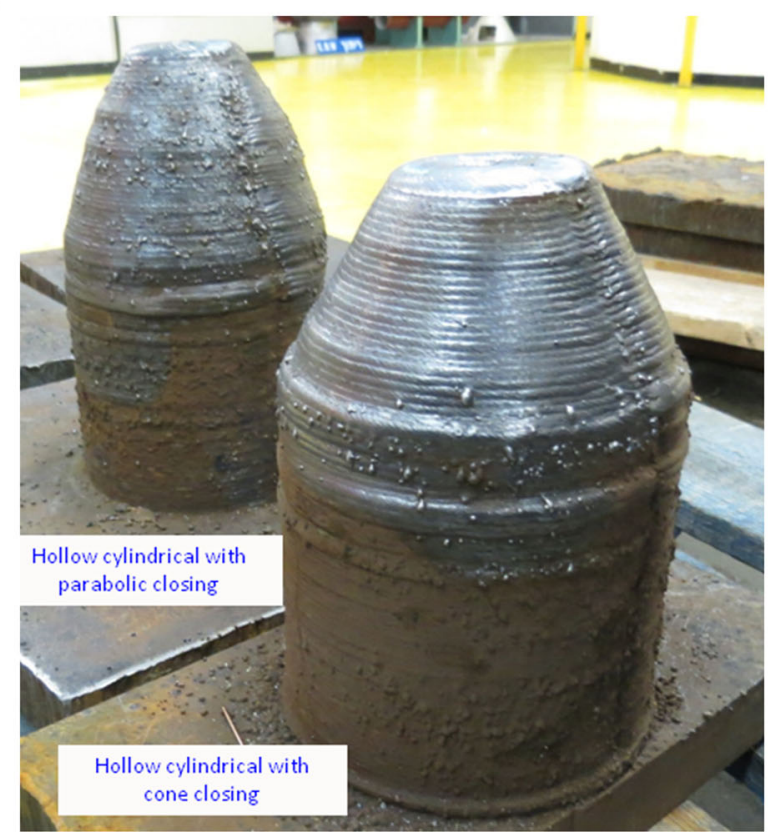

Fig. 3. (a) Schematic illustration of the GMAW robot and the tool path. (b) Typical cylinder for backward flow forming. (c) Closed cone and closed parabolic cylinders for forward flow forming.

preferences. ${ }^{15-19}$ To the best of our knowledge, there is as yet no means for obtaining the optimized path algorithm for path kinematics integrated with welding parameters to yield the best possible qualities and properties. In this work, a thick axisymmetric cylinder was built according to the path described in Fig. 2. The desired thickness of the parts was achieved by a sinusoidal weld tool oscillation with an amplitude A (wall thickness) and $m$ repeats in one circle with a radius $r$. This oscillation of the welding tool is well known in welding with wires for filling gaps in construction welding. This welding strategy allows variable welding seam definition using specific control parameters defining the oscillation amplitude (seam width) and frequency. Moreover, in this work, each 

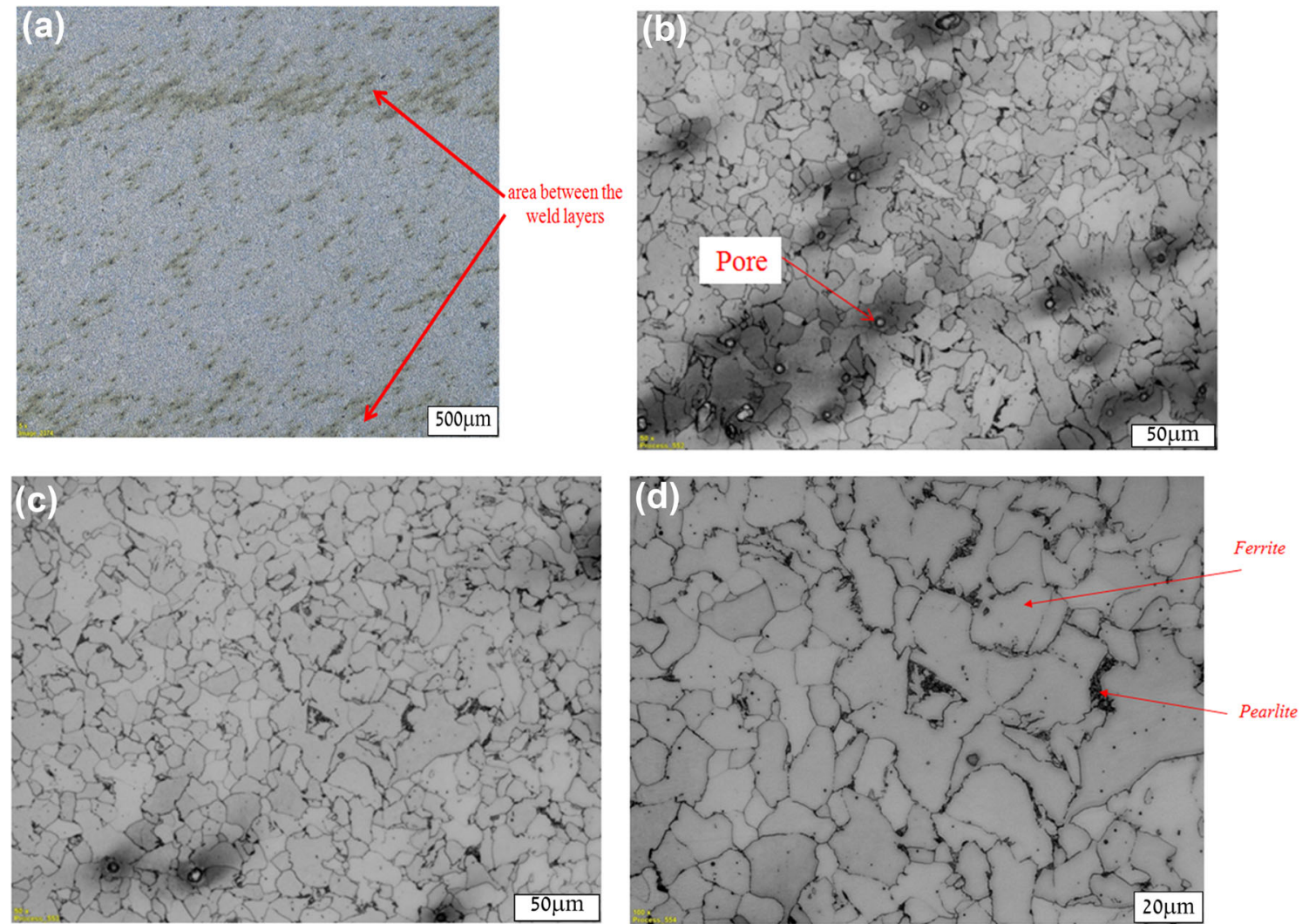

Fig. 4. Cross section of ER-70S-6 built structure: (a) macrostructure of the interface between layers (white scale bar $500 \mu \mathrm{m}$ ); (b) layer interface (white scale bar $50 \mu \mathrm{m}$ ); (c) layer center (white scale bar $50 \mu \mathrm{m}$ ); (d) higher magnification shows the material phases in the layer center (white scale bar $20 \mu \mathrm{m})$.

layer was realized separately to allow controlled cool-down time gaps between the layers as opposed to a continuous spiral approach.

\section{Preforms}

Two types of materials were used in the experimental part of this study, standard $\phi 1.2 \mathrm{~mm}$ AWS A5.18: ER-70S-6 and $\phi 1.14 \mathrm{~mm}$ AWS ER316L welding wires. The tool path generator as shown in Fig. 2 was implemented in each layer built. WAAM technology was used to manufacture near-net-shaped parts while exploring the crosslinkage between welding parameters and tool paths in determining the product qualities and properties.

A Cloos welding robot was used for the WAAM process. The cylindrical preform parts were built to a height of $120 \mathrm{~mm}$, a nominal mid-wall radius of $55 \mathrm{~mm}$ and a $15-\mathrm{mm}$ wall thickness. The welding parameters used were: current of $210 \mathrm{~A}, 23.9 \mathrm{~V}$; wire feed rate $6.10 \mathrm{~m} / \mathrm{min}$; pulse frequency $120 \mathrm{~Hz}$; robot tangential welding speed $14 \mathrm{~cm} / \mathrm{min}$. The shielding gas atmosphere used in the gas metal arc welding (GMAW) process was 98/2 [\% $\left.\mathrm{Ar} / \% \mathrm{O}_{2}\right]$. The tool path was derived from a CAD model that was sliced with a predetermined layer thickness of $2 \mathrm{~mm}$. The welding path strategy was applied, and tool path coordinates were incorporated into a G-code file for the welding manipulator.
Three major types of near-net-shape cylinder specimens were produced using the above two materials, as shown in Fig. 3. Open cylinders for backward flow forming as well as cylinders with closed cone ends and closed parabolic ends were used for forward flow forming. Each geometry was manufactured at least five separate times to demonstrate consistency of mechanical and metallurgical properties when the process is repeated under identical conditions.

\section{Chemical and Metallurgical Properties of the Material}

The chemical composition of the welding wires and the built parts was measured and compared with the AWS A5.18 standard for the ER-70S-6 and with the AWS: A5.18 standard for the AWS ER316L wires as shown in Table I. The chemical composition results indicate that the wires and parts composition comply with the applicable standards with the silicon level in the ER-70S-6 parts being slightly below the standard.

To illustrate imperfections, possible contamination and the metallurgical characteristics of the built parts, metallographic cross sections were prepared and are presented in Figs. 4 and 5. In the samples for metallurgical inspection, the slice was taken in the direction of construction and 
Table I. Chemical composition of wires and parts (wt.\%)

\begin{tabular}{|c|c|c|c|c|c|c|c|c|c|}
\hline & $\mathbf{C}$ & Mn & $\mathbf{S i}$ & $\mathbf{P}$ & $\mathbf{S}$ & $\mathbf{C u}$ & $\mathbf{N i}$ & $\mathrm{Cr}$ & Mo \\
\hline $\begin{array}{l}\text { Wire } \\
\text { ER-70S-6 }\end{array}$ & 0.079 & 1.56 & 0.89 & 0.016 & 0.006 & 0.104 & 0.009 & 0.018 & 0.002 \\
\hline Part & 0.072 & 1.248 & 0.761 & 0.015 & 0.0053 & 0.085 & 0.008 & 0.014 & 0.002 \\
\hline \multirow[t]{2}{*}{ AWS: A5.18 } & $0.06-0.15$ & $1.40-1.85$ & $0.80-1.15$ & $0.025 \max$ & $0.035 \max$ & $0.50 \max$ & $0.15 \max$ & $0.15 \max$ & $0.15 \max$ \\
\hline & $\mathbf{V}$ & $\mathbf{T i}$ & $\underline{\mathbf{Z r}}$ & Co & Al & Sn & $\mathbf{N}$ & \multicolumn{2}{|l|}{$\mathbf{F e}$} \\
\hline $\begin{array}{l}\text { Wire } \\
\text { ER-70S-6 }\end{array}$ & 0.003 & - & - & - & - & - & - & \multicolumn{2}{|l|}{ Rest (97.3) } \\
\hline Part & 0.0008 & 0.0032 & - & 0.0058 & 0.0064 & 0.0008 & 0.0066 & \multicolumn{2}{|l|}{97.7} \\
\hline \multirow[t]{2}{*}{ AWS: A5.18 } & $0.03 \max$ & - & - & - & - & - & - & - & - \\
\hline & $\mathbf{C}$ & Mn & Si & $\mathbf{P}$ & $\mathbf{S}$ & $\mathbf{C u}$ & $\mathbf{N i}$ & $\mathrm{Cr}$ & Mo \\
\hline $\begin{array}{l}\text { Wire } \\
\text { SS 316-L }\end{array}$ & 0.013 & 1.977 & 0.509 & 0.018 & 0.0010 & 0.157 & 11.50 & 19.22 & 2.426 \\
\hline Part & 0.024 & 1.852 & 0.444 & 0.020 & 0.0007 & 0.093 & 11.62 & 19.21 & 2.485 \\
\hline \multirow[t]{2}{*}{ ASME A5.9 } & $0.03 \max$ & $1.0-2.5$ & $0.30-0.65$ & $0.03 \max$ & $0.03 \max$ & $0.75 \max$ & $11.0-14.0$ & 18.0-20.0 & $2.0-3.0$ \\
\hline & $\mathbf{V}$ & $\mathbf{T i}$ & $\mathbf{W}$ & Cc & Al & $\mathbf{N b}$ & $\mathbf{N}$ & $\mathbf{F e}$ & \\
\hline $\begin{array}{l}\text { Wire } \\
\quad \text { SS 316-L }\end{array}$ & $\overline{0.069}$ & $\overline{0.004}$ & 0.014 & $0.0^{\prime}$ & 0 & 0.005 & 0.092 & $\overline{63.9}$ & - \\
\hline Part & 0.058 & 0.004 & 0.001 & 0.26 & 0 & 0.005 & 0.052 & 63.9 & - \\
\hline ASME A5.9 & - & - & - & - & - & - & - & - & - \\
\hline
\end{tabular}

Table II. Tensile properties of built materials

\begin{tabular}{|c|c|c|c|c|}
\hline Material & Yield strength (MPa) & Ultimate strength (MPa) & $\begin{array}{c}\text { Elongation } \\
(\%)\end{array}$ & Reduction of area (\%) \\
\hline ER-70S-6 & 360 & 480.7 & 36.7 & 78.0 \\
\hline ER-70S-6 AWS: A5.18 & 451 & 537 & 24 & - \\
\hline SS-316L & 334.4 & 588.5 & 40.2 & 64.3 \\
\hline SS-316L ASME: A5.9 & 170 & 485 & 35 & 39 \\
\hline
\end{tabular}

examines the interface between each layer built. Special attention was paid to the center of the layers and to the interfaces between the layers of the specimens. Figure $4 \mathrm{a}$ demonstrates a higher porosity at the interfaces between the layers than at the center of the layers. Although the typical pores found in photographs taken at higher magnifications (Fig. 4b and c) show that the diameter of the pores is approximately $5 \mu \mathrm{m}$ at this porosity level, the non-destructive ultrasonic tests could not identify those pores as defects, and the material could be considered fully dense. To confirm that these features were definitely pores (and not contaminants), the chemical compositions at the center of representative pores were tested and contaminated sites were excluded. A higher optical magnification of $1000 \times$ shown in Fig. $4 d$ reveals the structure of specimens that includes ferrite and pearlite phases. A cross section of the AWS ER316L built samples is presented in Fig. 5. The different layers in Fig. 5a represent the different cooling rates of the built layers. Higher magnification (Fig. 5b) showed dendrite-type grain growth during solidification of the welded layer.

The tensile properties measured in the built direction compared with the property wrought materials (given in Table II as the average results of five samples) indicate higher elongation and reduction of the area compared with the applicable standard weld materials.

Based on the tensile properties and metallurgical microstructure found in the measurements described above, no post-process thermal heat treatment was applied to the specimens prior to the flowforming operation. 

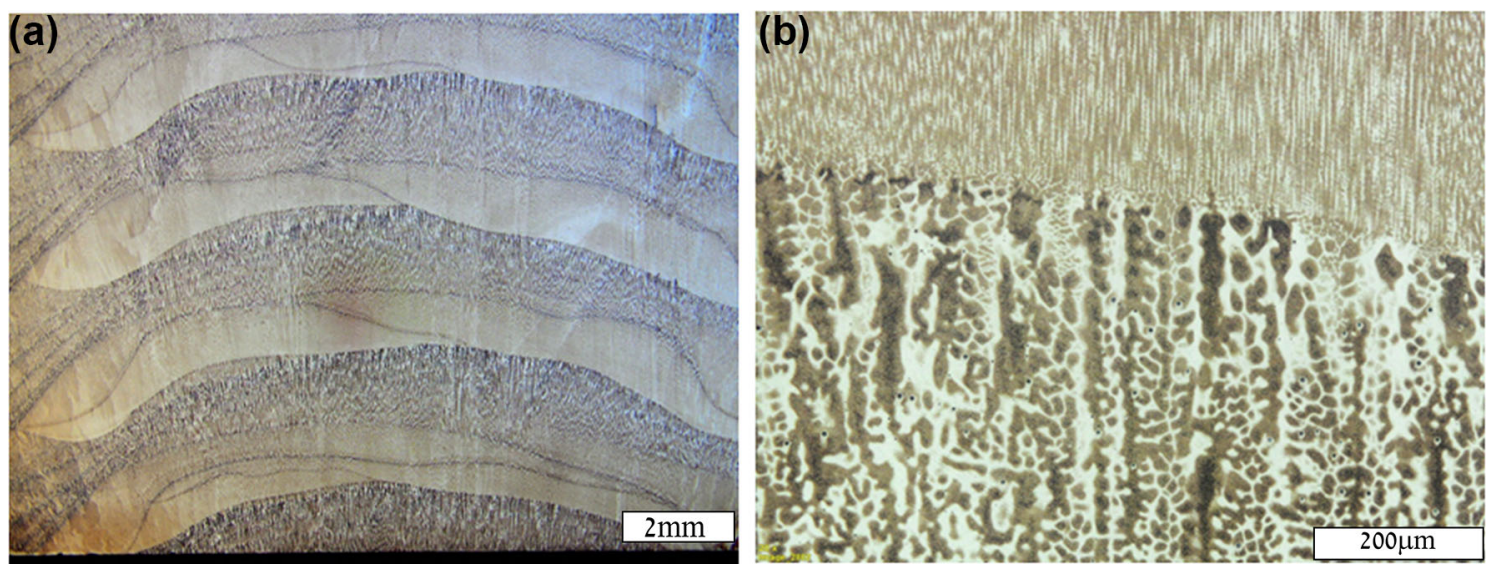

Fig. 5. Cross section of AWS ER316L built structure: (a) macrostructure of interface between layers; (b) high magnification shows dendrite-type growth during solidification.

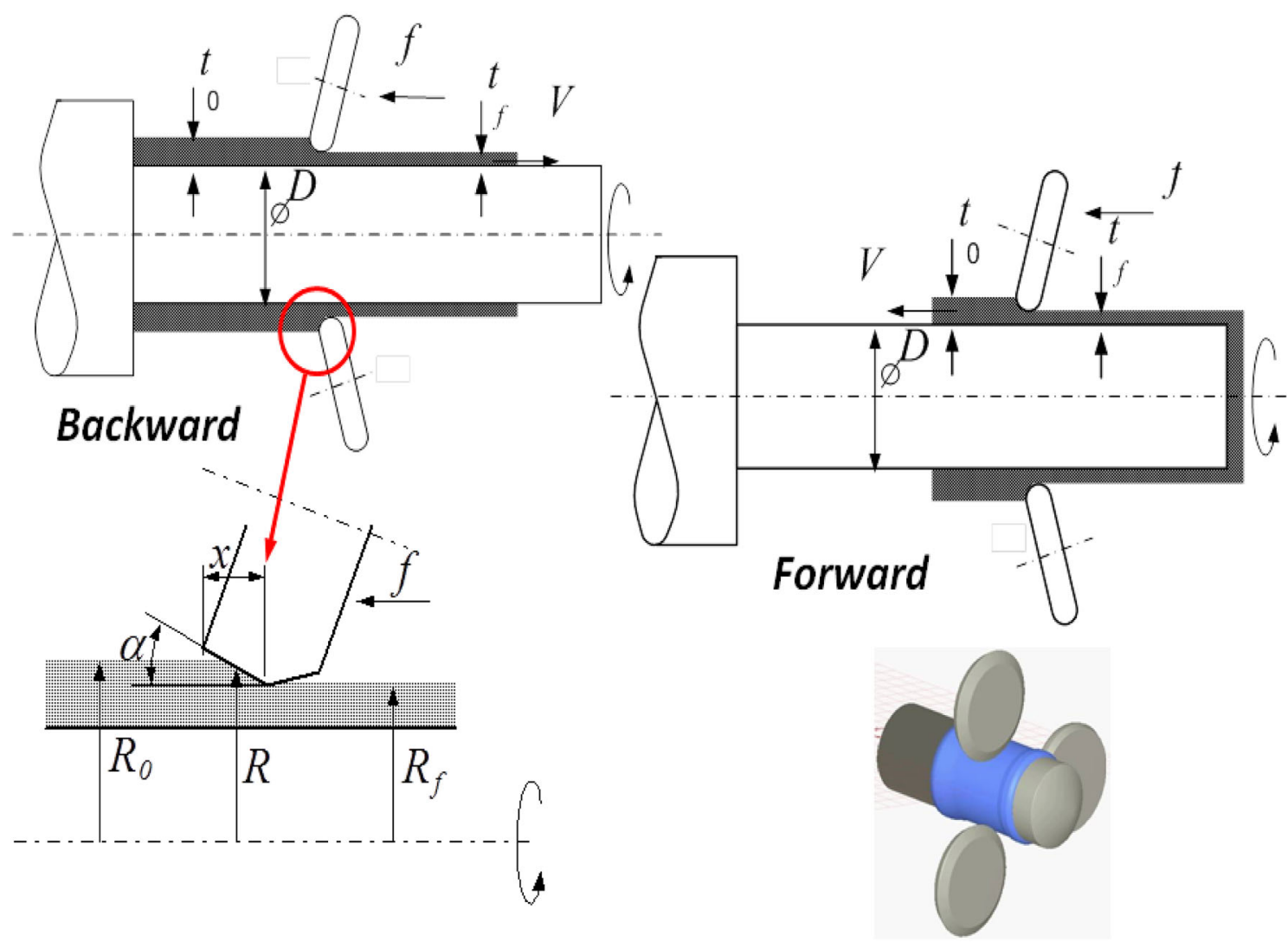

Fig. 6. Schematic illustrations of forward and backward flow forming.

\section{Flow Forming}

Schematic illustrations of forward and backward flow forming are shown in Fig. 6. These are very similar operations; however, Bhatt and Raval ${ }^{27}$ simulated differences between them: in forward flow forming, the axial and radial forces are higher than in backward flow forming; the circumferential force is higher in backward flow forming; the plastic strain distribution is higher along the thickness in forward flow forming, but higher along the length in backward flow forming.

In the work herin, the built parts were machined to comply with two initial flow-forming geometries: cylindrical tubes for backward flow forming and a cup shape for forward flow forming. In both cases, the inner diameter was $108.4 \mathrm{~mm}$, the wall 


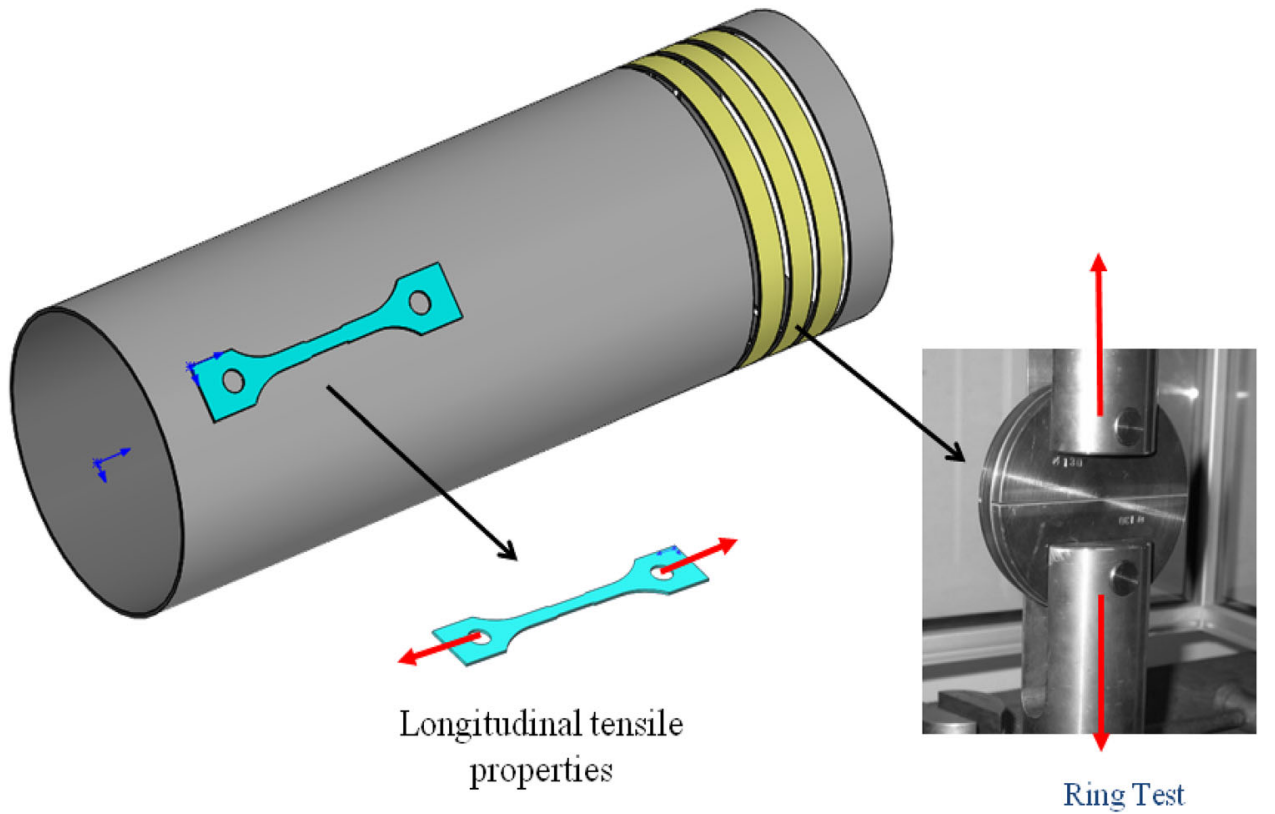

Fig. 7. Ring test and longitudinal tensile samples.

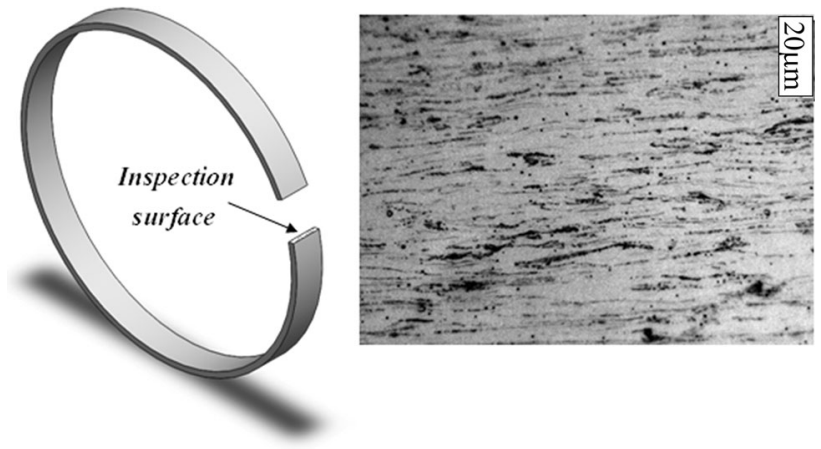

Fig. 8. Needle type macrostracture across a flow-formed ER-70s-6 tube with $83.6 \%$ thickness reduction. Owing to high plastic deformation, the material grains were anisotropic to the needles in the solidified shape (Fig. 4d).

thickness was $10-11 \mathrm{~mm}$, and the part was approximately $130 \mathrm{~mm}$ in length

The flow-forming operations were carried out using three stages of thickness reduction (ratio of final thickness to initial thickness): the first of $\sim 49 \%$; the second of $\sim 38 \%$; the third of $\sim 56 \%$. The feed rate to all stages was $0.74 \mathrm{~mm} / \mathrm{rev}$. The total reduction achieved was about $88 \%$.

Evaluating the average mechanical properties of the materials suggested the need for a three-stage flow-forming process protocol in both cases.

Representative specimens were allocated for destructive testing after the second and third flowforming stages. Longitudinal properties were tested using standard tensile samples (according to ASTM E8); tangential properties were tested using the tensile ring test. Flow-forming processes are known to significantly increase the tensile strength of the ring. Figure 7 shows from where the samples were taken. For each geometry and material, mechanical properties of three to five samples were examined to ensure repeatability of results. Table III summarizes the mechanical properties of the flow-formed tubes. Due to the strain hardening, the yield and ultimate strengths increase, while the elongation decreases. To examine the material strength, a bar was extracted from the parts at each process stage to evaluate its longitudinal and tangential material properties, composition and microstructure. Figure 7 illustrates the ring and longitudinal tensile specimen extraction from the tubes. The evaluation of the microstructure anisotrophy is shown in Fig. 8, which illustrates the needle-type macrostracture across a flow-formed ER70 S- 6 tube as result of $83.6 \%$ thickness reduction.

\section{CONCLUSION}

This work demonstrated the combination of WAAM and flow forming as a valid method for manufacturing seamless tubes using standard welding wires. Figure 9 illustrates backward flow-forming machined preformed and final tubes. The main conclusions are summarized as follows:

- ER-70s-6 and AWS ER316L stainless-steel welding wires were used as raw materials to manufacture a series of preformed parts for forward and backward flow-forming processes.

- Deep understanding and good tuning of the WAAM process yielded performed parts with material properties comparable or superior to those of conventional methods of manufacturing preforms using extrusion or forging processes followed by machining. 


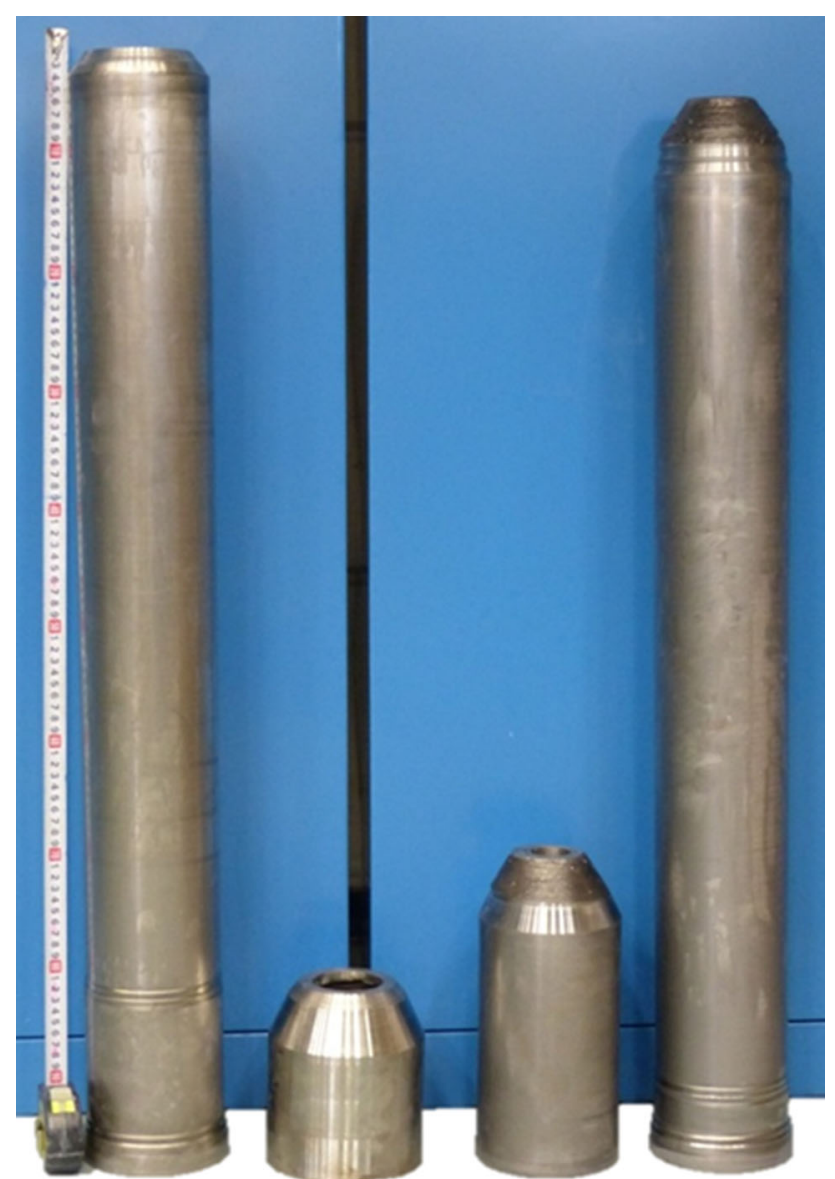

Fig. 9. Machined preformed and final tubes in backward flow forming (on the left are AWS ER316L parts and on the right ER70S-6 parts).
- The mechanical and metallurgical properties of the parts were examined in the as-built, after WAAM machining, and after plastic deformation phases of the second and third flow-forming stages.

- All measured parameters demonstrated acceptable or superior properties compared with conventional manufactured materials.

- This work demonstrates a new method of lean manufacturing of preformed parts for tube spinning using various materials. It has the potential to offer considerable savings in logistics as well as operational and economic benefits, in particular when applied to large parts or expensive materials; as an example, the lead time for extrusion or forging tools can be significantly diminished.

- Building of flow-forming preforms as near-net shapes reduced the machining time and material waste compared with machining of bulk materials.

- This newly proposed approach has potential to enable the use of different materials within a WAAM process session. By enabling in-session material changing, a new functional-driven design of property-specific, seamless tubes and other specimens can be considered.

The above conclusions open the window for new developments and the research required to establish the full scope of this approach. For instance, studies examining the fracture toughness and fatigue properties of this process outcome, as well as corrosion resistance and other relevant physical properties, are required.

Table III. Mechanical properties of ER-70S-6 and AWS ER316L as a function of thickness reduction and forming types

\begin{tabular}{|c|c|c|c|c|c|c|}
\hline Material & $\begin{array}{c}\text { Flow-forming } \\
\text { type }\end{array}$ & $\begin{array}{c}\text { Direction } \\
\text { (longitude/tangent) } \\
\end{array}$ & $\begin{array}{c}\text { Thickness } \\
\text { reduction } \\
(\%) \\
\end{array}$ & $\begin{array}{c}\text { Yield } \\
\text { strength } \\
\text { (MPa) } \\
\end{array}$ & $\begin{array}{c}\text { Ultimate } \\
\text { strength } \\
\text { (MPa) } \\
\end{array}$ & $\begin{array}{c}\text { Elongation } \\
(\%) \\
\end{array}$ \\
\hline \multirow[t]{8}{*}{ ER-70S-6 } & \multirow[t]{2}{*}{ Forward stage 2} & Longitude & 68.9 & \multirow[t]{2}{*}{763.6} & 799 & \multirow[t]{2}{*}{$*$} \\
\hline & & Tangent & 68.9 & & 785.4 & \\
\hline & \multirow[t]{2}{*}{ Forward stage 3} & Longitude & 87.8 & \multirow[t]{2}{*}{817.4} & 844.1 & \multirow[t]{2}{*}{6.2} \\
\hline & & Tangent & 87.8 & & 845.9 & \\
\hline & \multirow[t]{2}{*}{ Backward stage 2} & Longitude & 67 & \multirow[t]{2}{*}{671.6} & 731.4 & \multirow[t]{2}{*}{10.5} \\
\hline & & Tangent & 67.9 & & 749.4 & \\
\hline & \multirow[t]{2}{*}{ Backward stage 3} & Longitude & 83.8 & \multirow[t]{2}{*}{699.7} & 758.5 & \multirow[t]{2}{*}{9.0} \\
\hline & & Tangent & 83.8 & & 829.6 & \\
\hline \multirow[t]{8}{*}{ SS-316L } & \multirow{2}{*}{ Forward stage 2} & Longitude & 72 & \multirow{2}{*}{1004.5} & 1158.2 & \multirow[t]{2}{*}{10.6} \\
\hline & & Tangent & 72 & & 1270.9 & \\
\hline & \multirow[t]{2}{*}{ Forward stage 3} & Longitude & 88.6 & \multirow[t]{2}{*}{1083.1} & 1348.5 & \multirow[t]{2}{*}{6.9} \\
\hline & & Tangent & 88.6 & & 1496.8 & \\
\hline & \multirow[t]{2}{*}{ Backward stage 2} & Longitude & 68.7 & \multirow[t]{2}{*}{999.1} & 1146.4 & \multirow[t]{2}{*}{10.6} \\
\hline & & Tangent & 68.7 & & 1240.1 & \\
\hline & \multirow[t]{2}{*}{ Backward stage 3} & Longitude & 86.7 & \multirow[t]{2}{*}{878.6} & 1140.6 & \multirow[t]{2}{*}{11.3} \\
\hline & & Tangent & 86.7 & & 1413.6 & \\
\hline
\end{tabular}

*Sample broke close to the jig. 


\section{ACKNOWLEDGEMENTS}

The authors acknowledge the assistance of the technical staff of the Materials Processing group at Rafael Metal Technology Center for their technical assistance.

\section{REFERENCES}

1. K.M. Rajan and K. Narasimhan, Pract. Fail. Anal. 1, 69 (2001).

2. K.L. Motgharea, C.C. Handab, and R.L. Himtec, Int. J. Mech. Prod. Eng. 5, 124 (2017).

3. D. Marini, D. Cunningham, P. Xirouchakis, and J.R. Corney, Int. J. Mech. Eng. Technol. 7, 285 (2016).

4. M. Sivanadini, S.S. Dhami, and B.S. Pabla, Int. J. Sci. Eng. Res. 3, 1 (2012).

5. M. Gur and J. Tirosh, J. Eng. Ind. ASME Trans. 104, 17 (1982).

6. C.C. Wong and T.A. Deanb, J. Mater. Proc. Technol. 167, 344 (2005). https://doi.org/10.1016/j.jmatprotec.2005.05.039.

7. M.S. Mohebbi and A. Akbarzadeh, J. Mater. Proc. Technol. 210, 389 (2010). https://doi.org/10.1016/j.jmatprotec.2009.09. 028 .

8. M.H. Parsa, A.M.A. Pazooki, and M.N. Ahmadabadi, Int. J. Adv. Manuf. Technol. 42, 463 (2009). https://doi.org/10.1007/ s00170-008-1624-0.

9. K.M. Rajan, P.U. Deshpande, and K. Narasimhan, J. Mater. Proc. Technol. 125, 125 (2002). https://doi.org/10.1016/S092 4-0136(02)00305-9.

10. M.J. Davidson, K. Balasubramanian, and G.R.N. Tagore, J. Mater. Proc. Technol. 203, 321 (2008). https://doi.org/10.10 16/j.jmatprotec.2007.10.021.

11. B. Podder, C. Mondal, K.R. Kumar, and D.R. Yadav, Mater. Des. 37, 174 (2012). https://doi.org/10.1016/j.matdes.2012.0 1.002 .

12. R. Baker, Method of making decorative articles, U. S. Patent 1920:1. https://patents.google.com/patent/US1533300. Accessed 20 Sept 2018

13. K.S. Derekar, Mater. Sci. Technol. (2018). https://www. tandfonline.com/doi/full/10.1080/02670836.2018.1455012. Accessed Aug 2018.
14. W.E. Frazier, J. Mater. Eng. Perform. ASM Int. 2, 1917 (2014). https://doi.org/10.1007/s11665-014-0958-z.

15. D. Ding, Z. Pan, D. Cuiuri, and H.J. Li, in 4th International Conference on Robotic Welding, Intelligence and Automation (RWIA 2014), Shanghai, China (2014). https://doi.org/10.10 07/978-3-3139-18997-0_37.

16. Y.K. Bandari, S.W. Williams, J. Ding, and F. Martina, in 26th International Solid Freeform Fabrication Symposium, Austin, Texas, p. 17, 10-12 Aug 2015.

17. S. Williams, F. Martina, A.C. Addison, J. Ding, G. Pardal, and P. Colegrove, Mater. Sci. Technol. 32, 341 (2016). http s://doi.org/10.1179/1743284715Y.0000000073.

18. D. Ding, Z. Pan, D. Cuiuri, and H.J. Li, Int. J. Adv. Manuf. Technol. (2015). https://doi.org/10.1007/s00170-015-7077-3.

19. H. Lockett, J. Ding, S. Wiliams, and F. Martina, J. Eng. Des. 28, 568 (2017). https://doi.org/10.1080/09544828.2017.1365 826.

20. W.J. Sames, F.A. List, S. Pannala, R.R. Dehoff, and S.S. Babu, Int. Mater. Rev. (2017). https://doi.org/10.1080/09506 608.2015.1116649.

21. X. Xu, S. Ganguly, J. Ding, S. Williams, and F. Martina, Mater. Charact. (2017). https://doi.org/10.1016/j.matchar.20 17.12.002.

22. D. Schwam and B. Silwa, Final Report, Case Western Reserve University, Cleveland, OH Georgia Southern University, Statesboro, GA, October 2017.

23. R. Muvunzi, D. Dimitrov, S. Matope, and C. Kufazvinei (2016), https://www.researchgate.net/publication/32018766 7. Accessed 18 Oct 2018.

24. F. Martina, S.W. Williams, and P. Colegrove (2013), https:// www.researchgate.net/publication/262493669. Accessed 18 Oct 2018.

25. A. Prabakar, F. Martina, W. Suder, S. Ganguly, and S.W. Williams (2015), https://www.researchgate.net/publication/ 284721109.

26. J. Donoghue, A.A. Anyonysamy, F. Martina, P. Colegrove, S.W. Williams, and P.B. Prangnell, Mater. Charact. 114, 103 (2016). https://doi.org/10.1016/j.matchar.2016.02.001.

27. R.J. Bhatt and H.K. Raval, Bonfring Int. J. Ind. Eng. Manag. Sci. 5, 46 (2015). https://doi.org/10.9756/bijiems.80 53. 